\title{
DOSSIÊ
}

Sociologias, Porto Alegre, ano 19, no 46, set/dez 2017, p. 76-101

\section{Governança na pesquisa científica: reflexões sobre a prática da pesquisa contemporânea e a experiência brasileira}

ELIZABETH BALBACHEUSKY

\section{Resumo}

Tradicionalmente, a literatura sociológica faz uma clara distinção entre as abordagens que analisam o ensino superior e as mudanças que este vem experimentando nas últimas décadas, e as abordagens que analisam os fatos sociais relacionados à ciência, inclusive a sua institucionalidade. Entretanto, ciência e academia ocupam o mesmo espaço institucional: embora a pesquisa científica possa se organizar em outros espaços sociais, é inegável que, em todo o mundo, o ambiente acadêmico é o espaço privilegiado para a organização coletiva da ciência. A questão central do trabalho, portanto, é investigar a interação entre as mudanças experimentadas na governança universitária, as alterações recentes no modo de produção do conhecimento, e os novos modelos de governança da ciência. Em seguida, a análise se concentra nos dilemas que as dinâmicas dessas novas realidades criam para a experiência brasileira, com foco específico nos desenvolvimentos recentes do aparato institucional de coordenação da ciência e da universidade no Brasil.

Palavras-chave: Brasil. Universidade. Ciência. Governança universitária. Governança da ciência.

\footnotetext{
* Universidade de São Paulo, Brasil.
} 


\title{
Governance in scientific research: reflections on contemporary research practice and the Brazilian experience
}

\begin{abstract}
Traditionally, sociological literature makes a clear distinction between approaches in the analysis of higher education and the changes it has been experiencing in recent decades, and approaches in the analysis of the social facts related to science, including its institutionality. However, science and academia occupy the same institutional space: although scientific research can be organized in other social spaces, it is undeniable that, the academic environment is worldwide the privileged space for the collective organization of science. The central question of the work, therefore, is to investigate the interaction between changes experienced in university governance, recent changes in the mode of knowledge production, and new models of science governance. Following, the analysis focuses on the dilemmas created by the dynamics of these new realities for the Brazilian experience, focusing particularly on recent developments of the institutional apparatus for coordination of science and university in Brazil.
\end{abstract}

Keywords: Brazil. University. Science. University Governance. Governance of Science. 


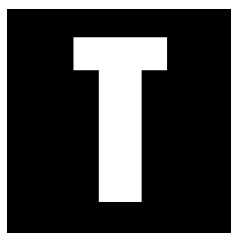

radicionalmente, a literatura sociológica faz uma clara distinção entre as abordagens que analisam o ensino superior e as mudanças que este vem experimentando nas últimas décadas, e as abordagens que analisam os fatos sociais relacionados à ciência, inclusive a sua institucionalidade. Entretanto, ciência e academia ocupam o mesmo espaço institucional: embora a pesquisa científica possa se organizar em outros espaços sociais, é inegável que, em todo o mundo, o ambiente acadêmico é o espaço privilegiado para a organização coletiva da ciência. Burton Clark (1986), em sua conhecida análise comparada dos grandes sistemas acadêmicos do mundo, registrava esse fato, apontando para a peculiar condição da institucionalidade da organização acadêmica, caracterizada por uma estrutura matricial, na qual parte das normas são produzidas internamente, a partir das dinâmicas de cada organização, enquanto que a outra parte é definida externamente, como reflexo da articulação horizontal de comunidades de pares, organizadas a partir de seus objetos de estudo e suas tradições de pesquisa e de produção de conhecimento.

Este trabalho pretende analisar os impactos das mudanças recentes experimentadas pelos sistemas acadêmicos em diferentes países, para depois refletir sobre seus efeitos sobre as formas de organização da profissão acadêmica e sobre a institucionalidade da ciência, incluindo as transformações experimentadas pelas universidade e ciência brasileiras.

\section{Dinâmicas recentes no ambiente acadêmico}

Desde as duas últimas décadas do final do século passado, o ensino superior vem experimentando mudanças estruturais de larga envergadura, que reconfiguram aquilo que usualmente entendemos como univer- 
sidade. Duas dinâmicas de longa duração parecem estar por trás dessas mudanças.

Em primeiro lugar, temos a expansão massiva do acesso ao ensino superior, com a constituição daquilo que Trow (2000) denominou sistemas universais de ensino superior. Essa expansão foi responsável pelo crescimento vertiginoso do peso dos custos do ensino superior nos orçamentos nacionais. Esse fato, por si só, seria suficiente para explicar o crescente interesse dos governos e do poder público por esse nível de ensino (Altbach, 1999; Teixeira, 2000; Musselin; Teixeira, 2013).

Por causa dessa expansão, as universidades perderam seu tradicional perfil elitista e esotérico. Até os anos setenta do século passado, ainda era possível falar da vida universitária como uma atividade orientada basicamente pelos seus próprios valores e propósitos, devotada a criar um espaço de autonomia capaz de assegurar a preservação, extensão e disseminação do conhecimento, tal como definido pelas regras da própria academia. Dentro dessa lógica, as universidades são, por necessidade, exclusivas. A própria natureza esotérica do conhecimento que justifica a existência dessa instituição lhe impõe só aceitar os candidatos à aprendizagem que reúnam as condições mínimas necessárias para participar dessa tradição (Pratt, 1997). Que essa seleção seja socialmente elitista é um elemento de menor importância nessa perspectiva. A questão central é garantir que apenas os melhores, os mais bem preparados, adentrem os muros da academia, e aí sejam iniciados. Que as injustiças de nossa sociedade terminem por excluir os filhos das famílias mais pobres, favorecendo filhos e filhas da classe média, média-alta, não é um argumento relevante para esse entendimento da natureza da universidade. A lisura do processo seletivo é central, porque ela assegura que apenas aqueles dispostos a estudar e se preparar serão aceitos nessa instância de formação que deve permanecer restrita. 
Daquela época para cá, a questão do acesso mudou de perspectiva. A demanda por equidade social ganhou força e, como resultado, tivemos uma vertiginosa expansão do acesso ao ensino superior e a adoção de mecanismos de inclusão que forçaram as universidades a abandonar a perspectiva elitista e autorreferenciada. Como resultado, as universidades, por toda parte, passaram a atender estudantes de origem mais diversificada e com um perfil de prontidão escolar e interesse muito mais heterogêneo, colocando relevantes desafios para que o acadêmico seja bem-sucedido no seu papel de professor. Essa mudança de longo prazo transformou significativamente aquilo que tradicionalmente se entende como a educação universitária.

Mais recentemente, a disponibilidade de amplos repositórios de informação, acessíveis a praticamente todos através da internet, e as novas tecnologias e ferramentas de aprendizagem vêm também transformando significativamente o modo como se concebe a educação: o ensino, aos poucos, retoma o lugar privilegiado que já ocupou no passado e é, crescentemente, uma especialidade que requer dedicação quase exclusiva. No passado, a introdução do livro impresso alterou significativamente o modo como a universidade concebia o ensino, que deixou de focar a leitura para enfatizar a interpretação. O mestre universitário deixou de ser um transmissor de conteúdos para se converter em intérprete do conhecimento existente (Nybom, 2007). A revolução tecnológica de que somos contemporâneos tem um impacto semelhante: do professor não se espera mais a simples discussão de conteúdos e a apresentação de técnicas especializadas - isso se tornou relativamente acessível. O que se espera da educação agora é o desenvolvimento de habilidades mais genéricas para a busca e manipulação criativa do conhecimento e da informação. As mudanças no tecido institucional da universidade provocadas por essa revolução apenas começam a ser notadas. Mas seu impacto deverá ser cada vez mais forte nas próximas décadas. 
A segunda dinâmica que está alterando significativamente o perfil das universidades decorre da expectativa generalizada na sociedade de que a Universidade desempenhe um papel ativo no desenvolvimento regional e cumpra uma função crucial nos processos que sustentam e ampliam a competitividade das economias nacionais nos mercados globais (Leydesdorff; Etzkowitz, 1996). De fato, desde o final dos anos oitenta do século passado, o ensino superior vem sendo redefinido como um dos elementos centrais dos sistemas nacionais de inovação (Lundvall, 1992). O ambiente criado pela acirrada competição nos mercados internacionais (Chesnais, 1992) contribuiu para reforçar a percepção da centralidade do papel que a universidade e o conhecimento nela produzido jogam para a inserção competitiva dos países na economia global (Archibugi; Lundvall, 2001). Por esse motivo, as universidades estão agora sob pressão crescente para desenvolverem relações estreitas com o setor empresarial e para oferecem uma formação de alto nível focada nas competências consideradas relevantes para o desenvolvimento do país.

A literatura também registrou o impacto dessas mudanças na institucionalidade da ciência e na configuração da profissão acadêmica. Em meados da década de noventa do século passado, o impacto desses processos na organização da atividade de pesquisa foi, pela primeira vez, alvo de uma análise sistemática. Essa análise apontou a emergência de um novo "modo de produção do conhecimento" (Gibbons et al. 1994), híbrido entre a pesquisa básica e a pesquisa aplicada, produzido por redes heterogêneas de pesquisa, baseado na transdisciplinaridade e governado por normas reflexivas que avaliam a qualidade do conhecimento produzido. $\mathrm{Na}$ época de sua publicação, o pequeno volume produzido por Gibbons e associados provocou grande controvérsia (por exemplo, Metzger; Zare, 1999; Leeuwen; Tijssen, 2000). O fato de que suas proposições estejam, até o presente, no centro de um vigoroso debate teórico que atravessou 
as duas últimas décadas é um poderoso indicativo da centralidade da questão levantada por esse estudo (Hessels; Lente, 2008).

Poucos anos depois, Etzkowitz e Leydesdorff (1995, 1997, 1998) chamaram a atenção para a emergência daquilo que denominam a "terceira missão da universidade", seu novo papel na articulação dos processos de inovação tecnológica e na mobilização do conhecimento para o desenvolvimento regional. Na mesma época, Donald Stokes (1994) propôs uma nova abordagem para a política de apoio à pesquisa, revisando o tradicional modelo linear que dominou essa política desde o pós-guerra. Segundo Stokes, ao contrário do pressuposto que embasou o famoso relatório de Vannevar Bush (1945), o foco no avanço do conhecimento básico não é incompatível com a preocupação com a sua aplicação. Para Stokes, o contexto de aplicação é, não raras vezes, um ambiente necessário para o avanço do conhecimento. Portanto, para esse autor, as políticas científicas do novo século deveriam focar a pesquisa que consegue simultâneamente fazer avançar o conhecimento fundamental e buscar ativamente alternativas para o seu uso, aquilo que ele chamou de "use-inspired basic research".

É interessante observar que, para essa primeira geração de trabalhos que discute as transformações na ciência contemporânea e seus efeitos sobre as universidades, as alterações no modo de produzir o conhecimento decorrem de pressões de fora para dentro, como resultados das mudanças ocorridas no ambiente social, econômico, político e mesmo cultural que cerca a ciência, de um lado, e a universidade, de outro. Mesmo a tão aclamada tendência à interdisciplinaridade é explicada mais como resultado de demandas vindas de atores externos à ciência, do que como produto de dinâmicas internas à própria produção do conhecimento científico.

Os trabalhos da segunda geração de estudiosos dessas mudanças apontam para outra direção. Em particular, os estudos de Bonaccorsi e 
associados (Bonaccorsi; Dario 2007; Bonaccorsi, 2008; Bonaccorsi; Vargas, 2010; Bonaccorsi et al. 2017) indicam que essas mudanças podem ser creditadas a alterações intrínsecas ao próprio campo de produção do conhecimento. De acordo com os pesquisadores da Escola de Engenharia da Universidade de Pisa, essas mudanças podem ser explicadas pelas alterações intrínsecas ao próprio processo de produção do conhecimento.

Segundo esses autores, as novas áreas científicas que emergem no final do século XX têm, todas, um ponto em comum: elas trabalham com objetos (sistemas) que são qualitativamente mais complexos do que os sistemas físicos e químicos explicados pelas áreas científicas mais antigas. Seu entendimento exige, simultaneamente, informações acerca dos elementos constituintes e de sua arquitetura. Ademais, essas áreas são caracterizadas por uma mudança radical na relação entre o natural e o artificial, quando o próprio momento do conhecimento e da observação se confunde com o design de novos artefatos. Finalmente, a produção do conhecimento nessas áreas depende da mobilização de grupos heterogêneos, tanto do ponto de vista cognitivo, como do ponto de vista de sua inserção institucional, o que exige um alto nível de complementaridade institucional: a produção do conhecimento depende criticamente do estabelecimento de fluxos de informação entre diversos tipos de dados que são produzidos por diferentes organizações. Mais recentemente, o estudo de Roosth (2017) permite-nos observar a explosiva criatividade que acompanha a dinâmica divergente (Bonaccorsi; Vargas, 2010) de produção do conhecimento, característica dessas áreas híbridas que nasceram no final do século passado e no início deste século. Os trabalhos dessa nova geração buscaram corroborar a hipótese de que as mudanças internas à ciência, produzidas pelas próprias exigências institucionais dos novos campos de conhecimento, jogam um papel relevante - e independente das pressões externas - para a reconfiguração do modo de produ- 
ção do conhecimento, o que se refletiria também em tensões sentidas no modelo de governança das ciências e das universidades.

\section{Governança universitária e governança da ciência}

Nos países que ocupam a liderança na produção do conhecimento científico contemporâneo, a universidade experimentou reformas profundas nas três últimas décadas. A literatura internacional (Musselin; Mignot-Gérard, 2002; Enders; De Boer; Weyer, 2012; Maassen; Olsen, 2007; Harman; Treadgold, 2007, entre outros) converge para o diagnóstico de que essas mudanças focam o modelo de governança das universidades, e têm como objetivo redefinir a autonomia universitária como autonomia organizacional. Isto é, elas buscaram dotar a universidade de algumas das características centrais que definem uma organização: uma identidade específica, acompanhada de maior controle sobre os recursos à sua disposição; a construção e reforço de hierarquias internas, visando aumentar a coordenação das ações dos múltiplos atores internos; e a adoção de uma racionalidade própria, capaz de assegurar intencionalidade nas suas decisões, reforçada pela identificação de objetivos definidos, como a missão específica da organização, e que devem ser compartilhados por todas as suas subunidades, orientando e articulando as decisões tomadas no interior da organização (Brunsson; Sahlin-Andersson, 2000). Em resumo, como sustentam Bleiklie, Enders e Lepori (2013):

Universities have traditionally been considered as a specific kind of institution with peculiar organizational characteristics such as decentralized internal authority vested in subunits and individual professors, and a high degree of organizational autonomy from outside interests (...) Recognizing the growing social and economic importance of higher education, reform politicians have tried to remove or modify these peculiarities, making them more alike business enter- 
prises that are generally being regarded as more cost effective forms of organizing large scale production processes, in this case aiming at more efficient production of educated candidates and research. (p. 1)

Simultaneamente, a governança da ciência tem experimentado mudanças igualmente relevantes. A melhor descrição do modo clássico de organização da governança da ciência foi apresentada por Michael Polanyi, em 1962. No seu clássico artigo, "A República da Ciência", publicado na primeira edição da revista Minerva (e republicado, em 2000, numa edição comemorativa da mesma revista), Polanyi apontava os mecanismos sutis que coordenam a atividade profissional de cientistas trabalhando em diferentes locais: os sinais sob a forma de publicações, que alimentam a convergência dos pesquisadores em torno dos padrões profissionais reconhecidos por uma área do conhecimento. As publicações não atestam simplesmente que o cientista está fazendo (bem) o seu trabalho. Elas representam pontos de interconexão de redes que desempenham um papel central na coordenação da atividade de cientistas que, de outra forma, permaneceriam isolados (Polanyi, 2000 [1962], p. 56).

Nesse modelo de governança, a ciência caminha bem, se deixada nas mãos da própria comunidade científica. A melhor forma de caracterizar a relação da ciência com a sociedade, nessa perspectiva, é uma delegação cega (blind delegation - Braun, 2003, p. 312), quando a sociedade entrega à comunidade científica todos os recursos e o direito de escolha sobre quais projetos, dentre os propostos pelos próprios cientistas, serão custeados.

Esse formato de governança assume que o conhecimento científico é um bem público que deve ter acesso irrestrito. Nessa perspectiva, qualquer tentativa para orientar a pesquisa científica para outros propósitos que não aqueles colocados pela própria ciência representa um obstáculo ao seu desenvolvimento (Polanyi, 2000 [1962]), p. 10). O que 
poucos reconhecem é que, nesse modo de governança, a ciência precisa se desenvolver contida dentro de linhas estritamente disciplinares, uma condição sine qua non para o efetivo controle da qualidade, exercido por comunidades de pares fortemente conectadas, que estabelecem as prioridades da pesquisa e, em função disso, o grau de relevância de um projeto proposto.

O trabalho pioneiro de Crane (1972) sobre a circulação do conhecimento no interior das redes de pesquisa trouxe evidências empíricas acerca do papel crucial que a articulação de uma rede estável e hierárquica (invisible colleges) joga para qualificar e organizar os resultados das pesquisas conduzidas por pesquisadores nesse modelo de governança. A sua conclusão, até o presente aceita pela literatura, é que a inserção do pesquisador em redes pouco articuladas tem efeitos deletérios para a qualidade e relevância do conhecimento que ele é capaz de produzir. Sem o suporte de uma rede forte e estruturada em torno de lideranças relevantes, a pesquisa perde seu caráter cumulativo e os pesquisadores passam a atuar num padrão circular, repetidamente revisitando velhas questões sem conseguir trazer novas perspectivas ou adicionar evidências significativas.

Entretanto, desde pelo menos meados dos anos oitenta do século passado, esse modelo de governança vem sofrendo repetidos e bem-sucedidos assaltos. Em primeiro lugar, temos as tentativas de orientar a pesquisa científica em direção a questões que são consideradas econômica ou socialmente relevantes. Essa outra forma de governança é antiga, foi seguidamente proposta e implementada por governos de orientação populista em todo mundo, e está na base do modelo de financiamento da ciência adotado, no passado, pelos governos de orientação soviética. A sua lógica básica consiste em singularizar determinados temas e questões, sinalizando que o Estado (ou uma agência pública ou privada) oferta recursos preferencialmente para pesquisas nesses temas. 
Como argumenta Braun (2003), esse modelo reproduz, no âmbito da política científica, todos os dilemas associados à clássica relação de delegação estudada pelo neoinstitucionalismo econômico (Williamson, 1973, 1976). A agência financiadora se comporta como um principal que busca formular prioridades para a agenda de pesquisa seguindo seus próprios interesses. O pesquisador se coloca na posição de agente, que executará a pesquisa. Nesse modelo, os cientistas preservam sua independência e mantém um interesse legítimo e genuíno em preservar sua carreira, que permanece informada pelo modelo clássico disciplinar da "ciência desinteressada" e que, por isso, tem dificuldades para valorizar os resultados produzidos por uma agenda de pesquisa desatrelada das prioridades colocadas pelos pares. Isso significa que o pesquisador tem poderosos incentivos para "camuflar" a sua própria agenda de pesquisa.

Do ponto de vista da política científica, caso a agência financiadora tenha um genuíno interesse em levar adiante sua agenda temática, essa situação requer investimentos pesados no desenvolvimento de mecanismos de avaliação e supervisão da atividade de pesquisa. Usualmente, entretanto, o compromisso da própria agência financiadora com a agenda de pesquisa politicamente motivada é baixo, e programas e/ou chamadas com temáticas específicas tendem a suplementar os mecanismos clássicos de financiamento, o que torna esse modelo de política muito pouco efetivo.

Um modelo de governança diferente ocorre quando o Estado busca alterar o próprio desenho da carreira do pesquisador. Em muitas experiências recentes, essa mudança foi associada às transformações experimentadas no âmbito da governança das universidades, descritas acima. Diferentes autores também identificaram mudanças dessa natureza, associadas à situação de escassez de recursos públicos, que limitaram a disponibilidade de fundos para apoiar a pesquisa entre os anos oitenta e noventa do século passado (Ziman, 1994; Senker, 2001). Entretanto, 
as evidências acumuladas ao longo das últimas décadas enfraquecem a hipótese de que as alterações documentadas no âmbito da governança universitária tenham produzido mudanças significativas na estrutura de valores que organiza a carreira acadêmica. De fato, como muitos estudos comprovam, acadêmicos, em diferentes países, continuam, como no passado, motivados pelos padrões e valores produzidos no interior das redes que organizam a produção do conhecimento. Os estudos conduzidos pela rede de pesquisa The Changing Academic Profession, que coletou dados em 19 países de todos os continentes, produziram evidências bastante convincentes de que hoje, tanto como no passado, os pesquisadores continuam fortemente motivados pelos sinais produzidos por suas comunidades de pares (Locke et al., 2011; Teichler et al. 2013).

Musselin e Mignot-Gérard (2002) argumentam que esse paradoxo é produzido pela natureza das atividades acadêmicas que seriam, na expressão das autoras, apenas fracamente coordenáveis - isto é, elas requerem apenas um baixo grau de cooperação e coordenação no âmbito da organização para serem executadas. Ademais, ensino e pesquisa seriam atividades pouco transparentes, já que são "difíceis de descrever, de prescrever e de reproduzir" (p.81). Essas características permitem que o acadêmico, individualmente, facilmente se furte aos controles desenvolvidos pela universidade reformada. Balbachevsky (2016) acrescenta uma outra dimensão fundamental para se entender essa situação paradoxal. Em sistemas de ensino superior maduros (Teichler et al., 2013), a carreira acadêmica no interior das universidades precisa refletir o prestígio que um acadêmico tem nas redes globais de produção do conhecimento. Sem uma reputação consolidada nessas redes, um acadêmico jamais conseguirá disputar um cargo mais expressivo nesses sistemas. Como vimos acima, a força e densidade das conexões entre a atividade acadêmica no interior de uma instituição e aquela desenvolvida por seus pares no ambiente glo- 
bal é um elemento central para assegurar a qualidade da atividade acadêmica. Num certo sentido, portanto, a atividade acadêmica coloca limites claros para as reformas "organizacionais" (organizatory reforms (sic)) descritas por Brunsson e Sahli-Andersson (2000, p. 730). Para permanecer relevante no contexto global da ciência, uma instituição acadêmica não pode prescindir dessas conexões, e, portanto, precisa preservar seu caráter de arena, isto é, aceitar que seus membros são "legitimamente guiados por interesses, valores, normas e padrões externos" (op. cit. p. 733).

No entanto, como vimos, a ciência contemporânea dá sinais de uma crescente "transgressividade" (Nowotny, 2003): ela é chamada a contribuir em debates que não podem ser resumidos aos aspectos puramente científicos ou técnicos. Seus interlocutores vão muito além da comunidade de especialistas. Para avançar, ela precisa interagir com uma gama ampla de atores, instituições, e negociar suas normas com audiências crescentemente heterogêneas. Os objetos de estudo que mobilizam essa ciência são complexos, não redutíveis à perspectiva de uma única disciplina. Mais do que isso, entretanto, a ciência contemporânea parece conviver com lógicas institucionais diversas (Dimaggio; Powell, 1983; Thornton et al., 2012) e, algumas vezes, opostas ou em competição.

Do ponto de vista do ambiente institucional que caracteriza a universidade, todas essas mudanças implicam, simultaneamente, a permeabilização dos seus limites e um aumento da complexidade do desenho institucional (Clark, 1998, Frølich et al., 2013). Essas dinâmicas contribuem para a emergência de novas lógicas institucionais no seu interior, que disputam espaço com o antigo modelo unificado, suposto pela universidade humboltiana. Para além da já tradicional contraposição entre o sistema de valores sustentados pela ciência tradicional, tal como descrita por Merton, e o da nova ciência "pós-acadêmica" analisada por Ziman (1994), é possível identificar a emergência de outros sistemas de valores igualmente podero- 
sos: o papel do "professor-didata", centrado na valorização das funções do ensino, formação e transmissão do conhecimento; o papel do pesquisador-ativista, focado nos desdobramentos políticos do conhecimento científico e engajado em atividades relacionadas com comunidades epistêmicas ativas (Adler; Haas, 1992). Os processos de conflito e acomodação entre essas lógicas institucionais constituem um elemento central para o entendimento dos desenvolvimentos recentes experimentados pelo ensino superior em escala mundial, e também no Brasil.

\section{Governança universitária e da ciência no Brasil}

Peter Maasen e Johan Olsen (2007) propuseram uma tipologia interessante para se entender as diferentes lógicas institucionais que predominam em diferentes arranjos de governança das universidades. A tipologia propõe distinguir as instituições universitárias considerando duas dimensões: o grau de convergência dos valores sustentados por diferentes atores internos acerca das normas e objetivos da instituição; e a relevância maior ou menor dos fatores externos na determinação das mudanças experimentadas pela instituição. Assim, a tipologia proposta por esses autores distingue 4 tipos diferentes de instituição universitária (quadro 1, abaixo): 
Quadro 1. Tipologia de instituições universitárias e suas dinâmicas de governança

\begin{tabular}{|c|c|c|}
\hline & $\begin{array}{c}\text { Dinâmicas institucionais } \\
\text { determinadas por fatores } \\
\text { internos }\end{array}$ & $\begin{array}{c}\text { Dinâmicas institucionais } \\
\text { determinadas por fatores } \\
\text { externos }\end{array}$ \\
\hline $\begin{array}{l}\text { Atores internos } \\
\text { compartilham } \\
\text { normas e } \\
\text { objetivos }\end{array}$ & $\begin{array}{l}\text { Modelo humboltiano: governo } \\
\text { de pares } \\
\text { Lógica: identidade } \\
\text { Critério de qualidade: relevância } \\
\text { científica } \\
\text { Dinâmica: com. científica }\end{array}$ & $\begin{array}{l}\text { Modelo instrumental } \\
\text { Lógica: administrativa } \\
\text { Critério de qualidade: resposta } \\
\text { às políticas } \\
\text { Dinâmica: decisões } \\
\text { governamentais }\end{array}$ \\
\hline $\begin{array}{l}\text { Atores têm } \\
\text { percepções } \\
\text { conflitivas sobre } \\
\text { normas e } \\
\text { objetivos }\end{array}$ & $\begin{array}{l}\text { Modelo democrático } \\
\text { Lógica: representação de } \\
\text { interesses } \\
\text { Qualidade: acomodação dos } \\
\text { interesses } \\
\text { Dinâmica: barganha interna }\end{array}$ & $\begin{array}{l}\text { Modelo Empreendedor Opera } \\
\text { em mercados competitivos, } \\
\text { Lógica: comunidade de serviços } \\
\text { Qualidade: responsividade } \\
\text { Dinâmica: respostas às pressões } \\
\text { competitivas do ambiente } \\
\text { externo }\end{array}$ \\
\hline
\end{tabular}

Nessa tipologia, o modelo humboltiano clássico é caracterizado por uma forte convergência de valores que sustentam fortes hierarquias de autoridade dentro da instituição. As decisões centrais da vida universitária estão a cargo do senado universitário, que funciona não como um espaço de representação, mas como uma assembleia de notáveis, que ocupam essa posição pela sua liderança intelectual, legitimada pelos seus pares, dentro e fora da universidade. No limite, esse modelo de governança supõe que a liderança científica está completamente alinhada à liderança institucional e que as dinâmicas da produção do conhecimento se organizam dentro de fronteiras disciplinares claras e conhecidas.

No modelo democrático, a autoridade se legitima porque é uma representação dos diferentes interesses presentes na instituição. O seu elemento organizativo básico é a eleição das autoridades universitárias, contando com a participação de todos os interesses internos à instituição. Nesse modelo, as dinâmicas da instituição respondem basicamente aos interesses dos diferentes setores internos que se fazem presentes no 
processo eleitoral. Tanto nesse modelo, como no modelo humboltiano, as interações da universidade com o ambiente externo respondem a uma agenda que é negociada no interior da instituição.

O terceiro tipo corresponde à universidade estatal, criada para responder a uma missão específica atribuída pelo Estado. Nessa lógica, a instituição universitária deve permanecer aberta às dinâmicas externas e seu sucesso é mensurado pela sua capacidade de resposta às demandas que vêm de fora. O modelo histórico que mais se aproxima desse ideal é o das universidades criadas pelos Estados socialistas do século passado e está presente na experiência chinesa dos dias atuais. Nessas instituições a lógica administrativa tende a predominar, e as dinâmicas internas da instituição são fortemente condicionadas e respondem às decisões tomadas no âmbito do Estado.

Finalmente, o quarto tipo ideal é aquele representado pela universidade empreendedora. A instituição está imersa num ambiente marcado pela competição, e suas subunidades estão submetidas à mesma lógica competitiva, e são estimuladas a explorar as oportunidades abertas no ambiente externo e interno. As oportunidades e riscos presentes nesse ambiente são o fator que mais claramente definem a trajetória de cada instituição. A experiência que mais se aproxima desse tipo ideal é a grande universidade de pesquisa norte-americana.

Uma análise do Quadro 1 (p. 91) acima permite-nos estabelecer o lugar da governança da universidade pública brasileira: ela é, predominantemente, organizada sob a lógica da representação de interesses. Suas autoridades são escolhidas e legitimadas pela consulta aos diferentes corpos (e interesses) que constituem os agentes internos da instituição. Nas universidades públicas brasileiras, a consulta, com a participação de todos os setores da universidade, é o mecanismo reconhecido e legitimado para se definir o controle da instituição. Mesmo no setor privado, a legitimida- 
de do modelo democrático é forte e tende a se reproduzir, em maior ou menor grau na maioria das instituições comunitárias. Sendo o princípio representativo dominante, as decisões, para serem legítimas, devem ser negociadas junto aos interesses internos à instituição.

Entretanto, se, aos olhos dos seus atores internos, a universidade brasileira é um espaço de representação de interesses, aos olhos da burocracia governamental, ela é, cada vez mais, um instrumento de política governamental. A experiência dos governos recentes sob a hegemonia do Partido dos Trabalhadores reformulou as bases da relação do Estado com a universidade pública no Brasil. Mesmo respeitando meticulosamente o espaço de autonomia da universidade, esses governos conseguiram fazer prevalecer sua agenda na condução da política universitária. O exemplo mais claro nesse sentido é o programa REUNI, que obteve sucesso em condicionar o acesso da universidade a recursos de investimento à implementação de programas de expansão da oferta de graduação, à adoção de políticas afirmativas, à consecução de metas relativas à proporção aluno/professor, etc. Da mesma forma, o Ministério da Educação foi bem-sucedido em sua política para centralizar os processos seletivos de acesso às universidades federais num único exame, o ENEM. Mais recentemente, o Congresso Nacional impôs uma política uniforme de ação afirmativa, criando cotas para estudantes de escolas públicas e para minorias em todas as universidades federais.

Dessa maneira, a governança das universidades públicas brasileiras tem passado por mudanças relevantes no que tange à sua imbricação com o ambiente externo: de um lado, pressões internas e mudanças no próprio modo de produção do conhecimento (Gibbons et al. 1994) empurram vários setores da academia a buscar conexões mais complexas com o seu entorno societal, desenvolvendo inclusive uma perspectiva empreendedora, que sustenta contatos relevantes com o mundo empresarial. Por 
outro lado, o bem-sucedido intervencionismo estatal recente concorre para criar uma realidade híbrida, que combina o modelo de governança baseado na representação de interesses com o modelo da universidade como instrumento de política nacional.

Todavia, a conjunção desses dois modelos de governança cria uma situação que reproduz, no âmbito das universidades, os clássicos problemas associados à relação de delegação que analisamos anteriormente. Em particular, o fato de a legitimidade da autoridade universitária ser concebida como uma representação a torna particularmente suscetível às pressões e contrapressões que nascem no interior dos diferentes corpos que são reconhecidos como igualmente legítimos na luta pela direção institucional. Nesse modelo, para ser legítima, uma decisão precisa ser traduzida num valor sustentado por um grupo majoritário dentro da instituição, e o argumento meritocrático é um dentre muitos outros valores igualmente legítimos, sustentados por diferentes partes da instituição. Assim, a relação entre universidade e governo, no Brasil, contém uma forte percepção de "moral-hazard" que se traduz num imenso esforço regulatório e avaliativo por parte do governo.

Da mesma forma, quando voltamos nossa atenção para a evolução da governança da ciência no Brasil, saltam aos olhos as mudanças que marcaram as décadas recentes. Se a primeira geração dessas políticas foi marcada pela lógica da delegação cega, a crise dos anos oitenta preparou caminho para alterações importantes nesse referencial. A escassez de recursos criou, pela primeira vez, uma pressão pela busca de novas fontes de financiamento da pesquisa, aproximando o meio acadêmico das grandes empresas estatais da época. Naquela época, a escassez dos recursos distribuídos pelas agências de apoio à pesquisa levou as muitas lideranças científicas a buscar ativamente acesso a outras burocracias e às empresas estatais, pondo em marcha os primeiros elementos de uma política marcada pela delegação por incentivos (Braun, 2003, p. 312) 
Nos anos noventa, as reformas empreendidas nas agências do MCT criaram um ambiente institucional mais favorável para a implantação sistemática de políticas associadas à delegação por incentivo. Internamente, essas reformas reforçaram as agências de fomento, sustentando a criação de competências institucionais necessárias para essa modalidade de política, notadamente competências de coordenação e de monitoramento. A nova conjuntura dos anos 2000 ampliou o espaço de ação de programas que atuam sob esse formato, ao mesmo tempo em que abriu espaço para as primeiras experiências com modelos de governança mais sofisticados.

A partir da segunda metade da primeira década do novo século, as agências de pesquisa passaram a experimentar novos modelos de governança científica, buscando articular redes que abrissem espaço para a participação e negociação da agenda de pesquisa com atores oriundos de diferentes ambientes institucionais, inclusive usuários e outros interesses societais. Esse é o modelo que alimentou os programas mais ambiciosos na área de ciência e tecnologia, inclusive os Institutos Nacionais de Ciência e Tecnologia. Esse programa propõe institucionalizar redes nacionais de cooperação focadas em temas de alta relevância para o enfrentamento de temas críticos para o futuro do país. Idealmente, essa estratégia deveria delegar as decisões e ações para os participantes das redes, criando oportunidades para a exploração de alternativas de interação, inovação e de aprendizagem institucional. Entretanto, na maior parte das experiências, essas redes foram bem-sucedidas do ponto de vista acadêmico. Elas articularam lideranças em diferentes universidades, impulsionaram a pesquisa e a produção acadêmica em geral, e, em particular, produziram estímulos importantes para a incorporação de jovens pesquisadores que estavam posicionados em instituições emergentes. Entretanto, seu sucesso em criar condições para a formação de uma agenda de pesquisa socialmente robusta (Nowotny, 2003) foi muito mais limitado. Da mesma forma, os 
resultados desses programas, em termos do desenvolvimento de novas institucionalidades no interior da universidade brasileira foram menos positivos. Vários fatores concorrem para esses resultados. Um elemento que não pode ser descartado é a relativa opacidade do ambiente interno das universidades brasileiras para as sinalizações mais dinâmicas que vêm de fora e uma tendência para encistar as pressões internas por mudança. Um survey realizado em 2007, junto a uma amostra representativa dos professores universitários brasileiros, mostrou que apenas $25 \%$ dos acadêmicos que trabalham nas universidades públicas acreditam que a qualidade das pesquisas é um fator relevante para as decisões internas relativas à contratação e promoção de professores (Balbachevsky; Schwartzman, 2011). Essa situação cria limites importantes para o amadurecimento de experiências mais dinâmicas, como é o caso das políticas que buscam apoiar a formação de redes de conhecimento e de outras estruturas que supõem a institucionalização, no âmbito da universidade, de espaços abertos a uma interação mais flexível entre diferentes atores comprometidos com a geração de novos conhecimentos e competências relevantes dentro e fora da academia. É bastante provável que essas condições concorram para dificultar a institucionalização de experiências mais flexíveis e inovadoras no âmbito do setor público do ensino superior brasileiro, especialmente quando se trata de universidades mais antigas.

\section{Conclusão}

Como assinalamos no início deste trabalho, usualmente, a literatura sociológica estabelece uma clara distinção entre as abordagens que analisam o ensino superior e aquelas que analisam os fatos sociais relacionados à ciência. Entretanto, na sociedade ocidental, ciência e academia ocupam, de fato, o mesmo espaço institucional, que é a universidade. Dessa forma, é 
inegável que as transformações experimentadas pela ciência e pelo ensino superior nas últimas décadas se influenciam mutuamente. Esse trabalho se debruça sobre as literaturas que, de um lado analisam as mudanças experimentadas pela universidade contemporânea, e de outro, discutem a emergência de novos modos de produção do conhecimento para investigar em que medida esses processos se condicionam mutuamente.

O objetivo desse esforço é mais o de lançar questões do que o de alcançar respostas, mas os resultados obtidos mostram que o esforço de lançar pontes entre essas linhas de estudo pode redundar em um programa de estudos frutífero e relevante.

A segunda parte do trabalho foca essa questão, considerando as experiências recentes vivenciadas pela universidade brasileira, considerando nossas experiências no que tange à governança institucional e no que tange à governança da pesquisa científica. Os resultados ainda são provisórios. Eles levantam questões que precisam ser investigadas. Ainda assim, a análise desenvolvida nesse trabalho pretendeu jogar uma luz nova sobre alguns dos dilemas mais importantes que se colocam para a universidade brasileira contemporânea.

Elizabeth Balbachevsky é professora da Faculdade de Filosofia Letras e Ciências Humanas, Departamento de Ciência Política, Universidade de São Paulo.

\balbasky@gmail.com 


\section{Referências}

1. ADLER, Emanuel; HAAS, Peter M. Conclusion: Epistemic Communities, World Order, and the Creation of a Reflective Research Program. International Organization, v. 46, n. 1, p. 367-90, 1992.

2. ALTBACH, Philip G. The Logic of Mass Higher Education. Tertiary Education \& Management, v. 5, n. 2, p. 107-24, 1999.

3. ARCHIBUGI, Daniele; LUNDVALL, Bengt-Åke. The Globalizing Learning Economy. London: Oxford University Press, 2001.

4. BALBACHEVSKY, Elizabeth. The Academic Profession in Latin America: Between a Corporatist and a Professional Ethos. In: HORTA, Hugo et al. (Eds.). Trends and Challenges in Science and Higher Education. Dordrecht: Springer, 2016, p. 103-17.

5. BALBACHEVSKY, Elizabeth; KERBAUY, Maria Teresa. A Governança universitária em transformação: a experiência das universidades públicas brasileiras. In: KOGA-ITO, Cristiane Y.; LUCA, Tania R. de. Escola UNESP de liderança e gestão: instrumento para excelência da gestão institucional. São Paulo: Cultura Acadêmica, 2016, p. 125-38.

6. BALBACHEVSKY, Elizabeth; SCHWARTZMAN, Simon. Brazil: Diverse Experiences in Institutional Governance in the Public and Private Sectors. In: LOCKE, William et al. (Eds.). Changing governance and management in higher education. Nova York: Springer, 2011. p. 35-56.

7. BLEIKLIE, Ivar; ENDERS, Jürgen; LEPORI, Benedetto. Introduction: Transformation of Universities in Europe. Higher Education, v. 65, n. 1, 2013. p. 1-4.

8. BONACCORSI, Andrea. Search regimes and the industrial dynamics of science. Minerva, v. 48, p. 285-315, 2008.

9. BONACCORSI, Andrea et al. The Solitude of Stars: An Analysis of the Distributed Excellence Model of European Universities. Jornal of Informetrics, v. 11, n. 3, p. 435-54, 2017.

10. BONACCORSI, Andrea.; THOMA, Grid. Institutional complementarity and inventive performance in nano science and technology. Research Policy, v. 6, n. 6, p. 813-31, 2007.

11. BONACCORSI, Andrea; DARAIO, Cinzia. Universities and Strategic Knowledge Creation: Specialization and Performance in Europe. Cheltenham: Edward Elgar Publishing, 2007.

12. BONACCORSI, Andrea; VARGAS, Juan. Proliferation Dynamics in New Sciences. Research Policy, v. 39, n. 8, p. 1034-50, 2010. 
13. BRAUN, Dietmar. Lasting Tensions in Research Policy-Making: a Delegation Problem. Science and Public Policy, v. 30, n. 5, p. 309-21, 2003.

14. BRUNSSON, Nils; SAHLIN-ANDERSSON, Kerstin. Constructing Organizations: The Example of Public Sector Reform. Organization Studies, v. 21, n. 4, p. 721-46, 2000.

15. BUSH, Vannevar. Science: The endless frontier. Washington: U.S. Government Printing Office, 1945.

16. CHESNAIS, François. National Systems of Innovation, Foreign Direct Investment and the Operations of Multinational Enterprises. In: LUNDVALL, Bengt-Åke. National Systems of Innovation: Toward a Theory of Innovation and Interactive Learning. Londres: Pinter Publishers, 1992, p. 259-92.

17. CLARK, Burton R. Creating Entrepreneurial Universities: Organizational Pathways of Transformation. Bingley: Emerald Group Publishing Limited, 1998.

18. CLARK, Burton R. The Higher Education System: Academic Organization in Cross-National Perspective. Oakland: University of California Press, 1986.

19. CRANE, Diana. Invisible Colleges: Diffusion of Knowledge in Scientific Communities. Chicago: University of Chicago Press, 1972.

20. DIMAGGIO, Paul J.; POWELL, Walter W. The Iron Cage Revisited: institutional isomorphism and collective rationality in organizational fields. American Sociological Review, v. 48, n. 2, 1983, p.147-60.

21. ENDERS, Jürgen; DE BOER, Harry; WEYER, Elke. Regulatory autonomy and performance: the reform of higher education re-visited. Higher Education, v. 65, n. 1, p. 5-23, 2012.

22. ETZKOWITZ, Henry; LEYDESDORFF, Loet. The Endless Transition: a 'Triple Helix' of University Industry Government Relations. Minerva, v. 36, n. 3, p. 2038, 1998.

23. ETZKOWITZ, Henry; LEYDESDORFF, Loet. Introduction to Special Issue on Science Policy Dimensions of the Triple Helix of University-Industry-Government Relations. Science and Public Policy, v. 24, n. 1, p. 2-5, 1997.

24. ETZKOWITZ, Henry; LEYDESDORFF, Loet. The Triple Helix-University-Industry-Government Relations: A Laboratory for Knowledge Based Economic Development. EASST Review, v. 14, n. 1, p. 14-9, 1995.

25. FRØLICH, Nicoline et al. A Reinterpretation of Institutional Transformations in European Higher Education: Strategising Pluralistic Organisations in Multiplex Environments. Higher Education, v. 65, n. 1, p.79-93, 2013.

26. GIBBONS, Michael et al. The New Production of Knowledge: The Dynamics of Science and Research in Contemporary Societies. Londres: Sage Publications, 1994. 
27. HARMAN, Kay; TREADGOLD, Elaine. Changing Patterns of Governance for Australian Universities. Higher Education Research \& Development, v. 26, n. 1, p. 13-29, 2007.

28. HESSELS, Laurens K.; VAN LENTE, Harro. Re-thinking new knowledge production: A literature review and a research agenda. Research Policy, v. 37, n. 4, p. 740-60, 2008. Disponível em: https://EconPapers.repec.org/RePEc:eee:respol: v:37:y:2008:i:4:p:740-760.

29. LEYDESDORFF, Loet; ETZKOWITZ, Henry. Emergence of a Triple Helix of university-industry-government relations. Science and Public Policy, v. 23, n. 5, Oct., 1996.

30. LOCKE, William; Cummings, William K.; FISHER, Donald. Changing Governance and Management in Higher Education: The Perspectives of the Academy. Nova York: Springer Science \& Business Media, 2011.

31. LUNDVALL, Bengt-Åke. (Ed.). National Innovation Systems: Towards a Theory of Innovation and Interactive Learning. Londres: Pinter Publishers, 1992.

32. MAASEN, Peter; OLSEN, Johan P. University Dynamics and European Integration. 1 ed. Dordrecht: Springer, 2007.

33. METZGER, Norman; ZARE, Richard N. Interdisciplinary research: From belief to reality. Science, v. 283, n. 5402, 642-3, 1999.

34. MUSSELIN, Christine. Are Universities Specific Organisations. In: KRUECKEN, Georg; TORKA, Marc. Towards a Multiversity? Universities between global trends and National traditions. New Brunswick: Transaction Publishers, p. 63-84, 2007.

35. MUSSELIN, Christine; MIGNOT-GÈRARD, Stéphanie. The Recent Evolution of French Universities. In: AMARAL, Alberto et al. (Eds.) Governing Higher Education: National Perspectives on Institutional Governance. Dordrecht: Kluwer, p. 63-85, 2002.

36. MUSSELIN, Christine. TEIXEIRA, Pedro. N. Reforming Higher Education: Public Policy Design and Implementation. Dordrecht: Springer, 2014.

37. NOWOTNY, Helga. Democratising Expertise and Socially Robust Knowledge. Science \& Public Policy, v. 30, n. 3, 2003.

38. NYBOM, Thorsten. A Rule-Governed Community of Scholars: The Humboldt Vision in the History of the European University. In: MAASSEN, Peter; OLSEN, Johan P. (Eds.). University Dynamics and European Integration, Serie Higher Education Dynamics, v. 19. Dordrecht: Springer, p. 55-80, 2007.

39. POLANYI, Michael. The Republic of Science: Its Political and Economic Theory. Minerva, v. 38, n. 1, p. 1-21, 2000 (1962). 
Sociologias, Porto Alegre, ano 19, no 46, set/dez 2017, p. 76-101

40. PRATT, John. The Polytechnic Experiment: 1965-1992. Bristol: Taylor \& Francis, 1997.

41. RHOADES, Gary. Capitalism, Academic Style, and Shared Governance. Academe, v. 91, n. 3, p. 38-42, 2005.

42. ROOSTH, Sophia. Synthetic: How Life Got Made. Chicago: The University of Chicago Press, 2017.

43. SENKER, Jacqueline. Changing Organisation of Public-Sector Research in Europe: Implications for Benchmarking Human Resources in RTD. Science and Public Policy, v. 28, n. 4, p. 277-84, 2001.

44. STOKES, Donald E. The Impaired Dialogue between Science and Government and What Might Be Done about It. In: TEICH, Albert H. et al. (Eds.), AAAS Science and Technology Policy Yearbook. Washington: AAAS, 1994, p. 123-45.

45. TEICHLER, Ulrich; ARIMOTO, Akira; CUMMINGS, William K. The Changing Academic Profession: major findings of a comparative survey. Dordrecht: Springer, 2013.

46. TEIXEIRA, Pedro Nuno. A Portrait of the Economics of Education, 1960-1970. History of Political Economy, v. 32, n. 5, 257-88, 2000.

47. THORNTON, Patricia H.; OCASIO, William; LOUNSBURY, Michael. The Institutional Logics Perspective: a new approach to culture, structure and process. Londres: Oxford University Press, 2012

48. TROW, Martin. From mass higher education to universal access: The American advantage. Minerva, v. 34, n. 4, 1999.

49. VAN LEEUWEN, Thed; TIJSSEN, Robert. Interdisciplinary dynamics of modern science: analysis of cross-disciplinary citation flows. Research Evaluation, v. 9, n. 3, p. 183-7, 2000.

50. WILLIAMSON, Oliver E. Markets and Hierarchies: Analysis and Antitrust Implications. Nova York: The Free Press, 1975.

51. WILLIAMSON, Oliver E. The Economic Institutions of Capitalism: Firms, Markets, Relational Contracting. Nova York: The Free Press, 1985.

52. ZIMAN, J. Prometheus Bound. Cambridge: Cambridge University Press, 1994.

Recebido: 05.05.2017

Aceite final: 31.05 .2017 